\title{
Vaginal colonization and activity of the probiotic bacterium Lactobacillus fermentum L23 in a murine model of vaginal tract infection

\author{
Correspondence \\ Liliana Pascual \\ Ipascual@exa.unrc.edu.ar
} \\ Received 3 May 2009 \\ Accepted 15 November 2009

\author{
Liliana Pascual, ${ }^{1}$ Francisco Ruiz, ${ }^{1}$ Walter Giordano ${ }^{2}$ \\ and Isabel Lucila Barberis ${ }^{1}$
} \\ ${ }^{1}$ Departamento de Microbiología e Inmunología, Universidad Nacional de Río Cuarto (UNRC), 5800
Río Cuarto, Córdoba, Argentina \\ ${ }^{2}$ Departamento de Biología Molecular, UNRC, 5800 Río Cuarto, Córdoba, Argentina

\begin{abstract}
A strain of Lactobacillus, identified as Lactobacillus fermentum L23, was selected from among 100 strains isolated from vaginal swabs of healthy, non-pregnant, pre-menopausal women. L. fermentum L23 was chosen on the basis of its bacteriocinogenic ability and its properties relevant to colonization, i.e. self-aggregation, adherence to vaginal epithelial cells and coaggregation with bacterial pathogens. The antimicrobial preventative and curative effects produced by the probiotic $L$. fermentum L23 administered locally against Escherichia coli in a murine vaginal tract infection model were studied. One dose of the human strain $\mathrm{L} 23$ containing $10^{8}$ c.f.u. $\mathrm{ml}^{-1}$ colonized and persisted in the vaginal tract of the female BALB/c mice for 5 days. Infection with the pathogen at $10^{6}$ c.f.u. $\mathrm{ml}^{-1}$ in the vaginal tract was maintained for more than 7 days. A single dose of L23 administered 24 h pre-infection inhibited $E$. coli growth on day 3 post-infection, showing the preventative effect displayed by this Lactobacillus strain. Treatment with $L$. fermentum L23 during the post-infection period showed complete inhibition of pathogen growth from day 5 . Thus, this in vivo study indicated that the probiotic bacterium $L$. fermentum L23 produced both preventative and curative effects on E. coli growth. The beneficial properties and the production of antimicrobial metabolites may act in situ to inhibit a pathogenic microorganism within the vaginal environment. Strain L23 could be a good natural alternative to other therapies used for genital infections.
\end{abstract}

\section{INTRODUCTION}

Lactobacilli are the predominant micro-organisms in the vaginal tract of humans and some homeothermic animals. They can maintain the ecological equilibrium of the tract by protecting against pathogenic micro-organisms. The physiology of the urogenital tract may change during the natural history of humans and animals, with an accompanying modification of the normal microbial flora (Vintiñi et al., 2004).

Certain species of lactic acid-producing bacteria are promoted as probiotic, live micro-organisms that may be ingested to produce beneficial effects on human well-being. An important benefit of probiotics is the capacity to curtail or prevent infectious diseases (Wagner et al., 1997a; Colodner et al., 2003; Reid et al., 2003, 2005). Studies have shown a correlation between loss and disruption of the normal genital microflora, in particular Lactobacillus species, and increased incidence of genital infections (Reid,

The GenBank/EMBL/DDBJ accession number for the 16S rRNA gene sequence of $L$. fermentum $L 23$ is GQ455406.
2002; Pascual et al., 2008a, b). The normal vaginal flora of healthy females can competitively block the in vitro attachment of pathogenic bacteria (Chan et al., 1985). Pre-clinical and clinical reports have focused on lactobacillus strains, their possible prophylactic effects against experimental Escherichia coli infection and the use of these strains for the prevention of human urogenital infections (Asahara et al., 2001).

Our research group selected the human Lactobacillus fermentum strain L23 as a promising probiotic based on its ability to produce bacteriocin and its wide antimicrobial activity against several clinical micro-organisms. The inhibitory effect of L23 on bacterial growth was not altered by heat treatment, and all samples showed inhibitory activity over a wide $\mathrm{pH}$ range $(\mathrm{pH} 4.0-7.0)$ with optimal activity at $\mathrm{pH} \mathrm{5.5;} \mathrm{trypsin} \mathrm{treatment} \mathrm{eliminated} \mathrm{the}$ inhibitory activity. Moreover, strain L23 displayed in vitro properties relevant to colonization, i.e. high hydrophobicity, as assessed by a salt aggregation test, self-aggregation, adherence to vaginal epithelial cells and co-aggregation with pathogenic micro-organisms (Pascual et al., 2008a). 
In the present study, female $\mathrm{BALB} / \mathrm{c}$ mice were used as an animal experimental model in pre-clinical studies. We have described a vaginal murine infection model, and investigated the antimicrobial preventative and curative effects produced by the probiotic L. fermentum L23 administered locally against $E$. coli.

\section{METHODS}

Pathogenic strain. A uropathogenic strain of E. coli was isolated from a patient with cystitis, identified by standard bacteriological procedures, maintained in brain heart infusion broth and stored at $-70{ }^{\circ} \mathrm{C}$.

It was identified as E. coli by Gram staining followed by standard biochemical tests (Bergey's Manual of Determinative Bacteriology, 1994), and was cultured on eosin/methylene blue (EMB) agar (Britania), under optimal conditions of incubation for $24-48 \mathrm{~h}$ at $37{ }^{\circ} \mathrm{C}$. This strain was used as an indicator strain in the antimicrobial activity assays.

Lactobacillus strain. A L. fermentum strain was isolated from a healthy woman's vagina and grown overnight at $37^{\circ} \mathrm{C}$ in ManRogosa-Sharpe (MRS) medium (Biokar Diagnostics) or on plates of MRS medium supplemented with $1.5 \%$ agar under limited aerobic conditions. The strain was identified by standard biochemical tests (Bergey's Manual of Determinative Bacteriology, 1994) and an API 50 $\mathrm{CH}$ biochemical identification system (bioMérieux) (Nigatu et al., 2000). The 16S rRNA gene was sequenced with an Applied Biosystems model 3730XL automated DNA sequencing system by Macrogen Laboratories (Korea). The 16S rRNA gene sequence was subjected to a BLAST search (www.ncbi.nlm.nih.gov/BLAST/) to find identities between sequences.

Mice. For this experimental model, 7-week-old female BALB/c mice were used. Mice received a normal diet and water ad libitum, and were kept in isolation cubicles at a constant temperature of $24{ }^{\circ} \mathrm{C}$, with a cycle of $12 \mathrm{~h}$ fluorescent light/ $12 \mathrm{~h}$ darkness. First, we surveyed the micro-organisms that naturally inhabit the $\mathrm{BALB} / \mathrm{c}$ mouse vagina. The microbiota of the mice was studied from vaginal samples taken with swabs. Swabs were cultured at $37{ }^{\circ} \mathrm{C}$ on plates of MRS agar under partial $\mathrm{CO}_{2}$ tension, $5 \%$ blood agar (bioMérieux) and $\mathrm{EMB}$ agar. Strains grown on MRS and EMB agar plates were identified by standard diagnostic procedures (Lennette et al., 1987; Bergey's Manual of Determinative Bacteriology, 1994; Forbes et al., 2004).

Four groups were included in this study with nine mice per group. The first group was used to study microbial colonization by the $L$. fermentum strain L23, the second one for vaginal infection with E. coli and the other two groups for determining preventative and curative effects.

Microbial colonization. L. fermentum strain L23 was cultivated in MRS broth at $37^{\circ} \mathrm{C}$ for $24 \mathrm{~h}$, washed with distilled water, resuspended in PBS ( $\mathrm{pH}$ 6.7) and adjusted to an approximate concentration of $5 \times 10^{8}-1 \times 10^{9}$ c.f.u. $\mathrm{ml}^{-1}$ by comparison with McFarland turbidity standards. A $20 \mu \mathrm{l}$ inoculum of the lactobacillus suspension was infused into the vaginal tract using a micropipette. From the same suspension, serial dilutions were performed, and $20 \mu \mathrm{l}$ aliquots were inoculated onto MRS agar plates (c.f.u. $\mathrm{ml}^{-1}$ at $T_{0}$ ). The microbial colonization of the mice was monitored on days $1-7$ by counting colonies of viable bacteria (c.f.u.) recovered from the vaginal fluids from mice, and serially diluted. To determine the c.f.u., each dilution was inoculated onto MRS agar plates. The plates were incubated for $24 \mathrm{~h}$ at $37{ }^{\circ} \mathrm{C}$ under partial $\mathrm{CO}_{2}$ tension. The number of c.f.u. was expressed as $\log _{10}$ c.f.u. (ml vaginal fluid) ${ }^{-1}$ (Wagner et al., 1997a, b).

Vaginal infection. Mice were infected by vaginal inoculation with $20 \mu \mathrm{l}$ of the suspension of $E$. coli adjusted to $1 \times 10^{6}$ c.f.u. $\mathrm{ml}^{-1}$ in PBS. Samples were collected from all of the mice and serial dilutions were performed. Subsequently, bacteria were cultured on EMB agar plates under optimal conditions of incubation. Infection levels on days 1-7 after inoculation were evaluated by quantifying the number of viable cells. Results were expressed as $\log _{10}$ c.f.u. $\mathrm{ml}^{-1}$.

Preventative effect. The preventative effect of L. fermentum L23 administered into the murine vaginal tract was examined. A single dose $(20 \mu \mathrm{l})$ of $L$. fermentum $\mathrm{L} 23$ containing $1 \times 10^{8}$ c.f.u. $\mathrm{ml}^{-1}$ was inoculated into the vagina of mice $24 \mathrm{~h}$ before infection with $E$. coli. Vaginal infection was induced by intra-vaginal administration of $20 \mu \mathrm{l} \mathrm{E}$. coli at $1 \times 10^{6}$ c.f.u. $\mathrm{ml}^{-1}$ in PBS. To determine the number of viable cells of lactobacilli and E. coli, vaginal samples were collected daily for 7 days. The number of lactobacilli from each dilution was determined on MRS agar plates incubated for $24 \mathrm{~h}$ at $37^{\circ} \mathrm{C}$ under partial $\mathrm{CO}_{2}$ tension, and the number of viable lactobacilli was expressed as $\log _{10}$ c.f.u. (ml vaginal fluid) ${ }^{-1}$. EMB agar plates were used to determine the number of viable $E$. coli cells from serial dilutions of the vaginal samples. The plates were incubated aerobically for $24 \mathrm{~h}$ and the results were expressed as $\log _{10}$ c.f.u. $\mathrm{ml}^{-1}$.

Curative effect. To perform the E. coli infection, $20 \mu \mathrm{l}$ of the suspension of $E$. coli adjusted to $1 \times 10^{6}$ c.f.u. $\mathrm{ml}^{-1}$ in PBS was vaginally inoculated. At $48 \mathrm{~h}$ post-inoculation, a $20 \mu \mathrm{l}$ aliquot of lactobacilli at $5 \times 10^{8}$ c.f.u. $\mathrm{ml}^{-1}$ in PBS was infused into the vagina. To evaluate the curative activity, serial dilutions of vaginal swabs were cultured daily for 7 days on EMB and MRS agar plates. L. fermentum L23 was incubated under limited aerobic conditions for $24 \mathrm{~h}$, whereas in the case of $E$. coli aerobic conditions were required.

Statistical analysis. All bacterial counts were expressed as means $\pm S D$ and were log-transformed for each experiment. An analysis of variance (Sigma Stat Statistical Software version 2.0, for Windows NT and 3.1; SPSS) was used for differences in numbers of viable micro-organisms from various treatment groups. A $P$ value of $<0.05$ was considered statistically significant.

\section{RESULTS}

Microbiological analysis of normal flora in mice from vaginal samples was performed by light microscopy and culture on agar plates. Gram staining of direct sample slides showed the limited presence of Gram-positive cocci and bipolar bacilli. These observations correlated with the white colonies that grew on blood agar plates under aerobic conditions. There was no growth on MRS or EMB plates. This indicated an absence of lactobacilli and E. coli strains.

The study of vaginal colonization by lactobacilli showed that the human L. fermentum L23 strain had the ability to colonize the vaginal tract. A single inoculation was sufficient to establish the probiotic lactobacilli in that niche. L. fermentum L23 vaginal tract levels remained fairly high for 4 days, with bacterial levels ranging from 4.6 to $3.8 \log _{10}$ c.f.u. $\mathrm{ml}^{-1}$. On day 5 , values decreased to $2.6 \log _{10}$ c.f.u. $\mathrm{ml}^{-1}$. No growth of the L23 strain was observed thereafter (Fig. 1).

E. coli infection in a murine vaginal tract model was examined. This infection was induced by vaginal admin- 


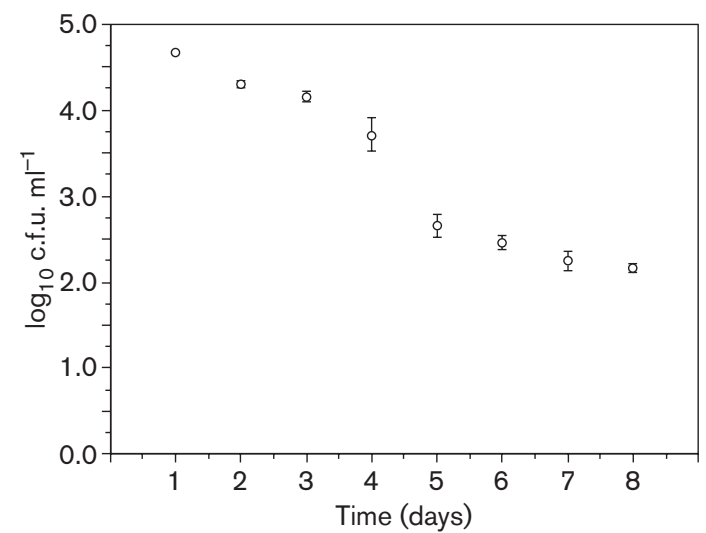

Fig. 1. Vaginal colonization of $L$. fermentum $L 23$ in BALB/c mice. Results are shown as means \pm SD.

istration of E. coli at $1 \times 10^{6}$ c.f.u. $\mathrm{ml}^{-1}$ in PBS. Infection with the pathogen was maintained in the vaginal tract for more than 7 days (Fig. 2), and this human E. coli uropathogenic strain was able to produce a strong infection when inoculated at this concentration, producing significant morphological alterations of the mucosal structure, mainly due to infiltration of polymorphonuclear cells.

The test on the preventative effect produced by strain L23 on the vaginal infection with $E$. coli showed that a single administration of the lactobacillus at $1 \times 10^{8}$ c.f.u. $\mathrm{ml}^{-1}$ inhibited E. coli growth from 4.1 to $3.4 \log _{10}$ c.f.u. $\mathrm{ml}^{-1}$ on the second day after infection (day 3 after L23 inoculation; Fig. 3). On the third day post-infection, E. coli growth was not detected, showing that the pathogen was eliminated by the probiotic strain in this animal model (Fig. 3). A significant difference between the untreated control (Fig. 2) and the treated group (Fig. 3) was found $(P<0.05)$.

To evaluate the curative effect produced, L23 was inoculated $48 \mathrm{~h}$ after the E. coli inoculation. At a

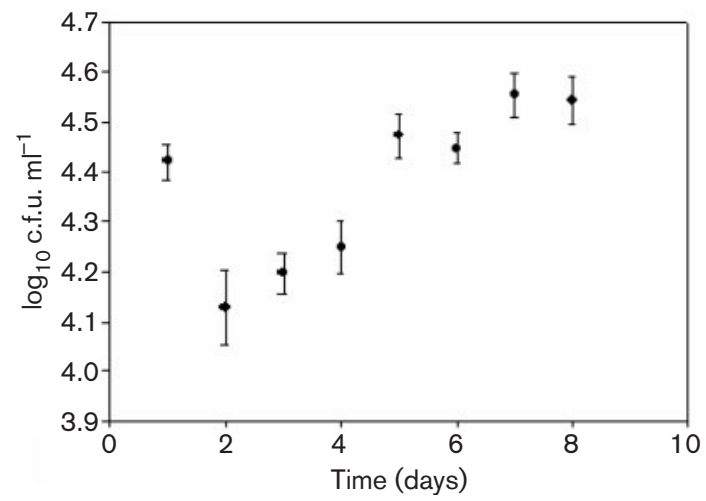

Fig. 2. Vaginal infection of $E$. coli in female mice. Results are shown as means \pm SD.

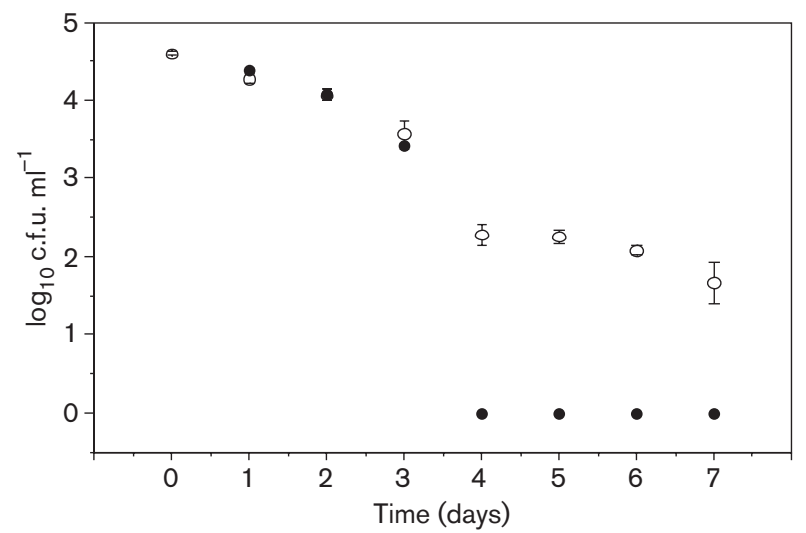

Fig. 3. Preventative effect of $L$. fermentum L23 ( $\bigcirc)$ on E. coli ( () in BALB/c mice. Results are shown as means \pm SD. Significant differences between the untreated control (Fig. 2) and the treated group were found $(P<0.05)$.

concentration of $1 \times 10^{8}$ c.f.u. L2 $3 \mathrm{ml}^{-1}$, the E. coli growth rate decreased from 4.4 to $2.3 \log _{10}$ c.f.u. $\mathrm{ml}^{-1}$ on day 4 after lactobacillus administration into the vagina of the mice. Complete inhibition of pathogen growth was observed on day 5 after treatment with L23 (Fig. 4). Thus, $L$. fermentum at a concentration of $1 \times 10^{8}$ c.f.u. $\mathrm{ml}^{-1}$ effectively eliminated E. coli from the vagina and caused no damage.

\section{DISCUSSION}

Many new experimental therapies have been studied recently in in vivo models mainly using lactobacilli strains as probiotics (Alander et al., 1999; Kontiokari et al., 2001; de Champs et al., 2003; Peran et al., 2007). Probiotic micro-organisms function, in general terms, by limiting the

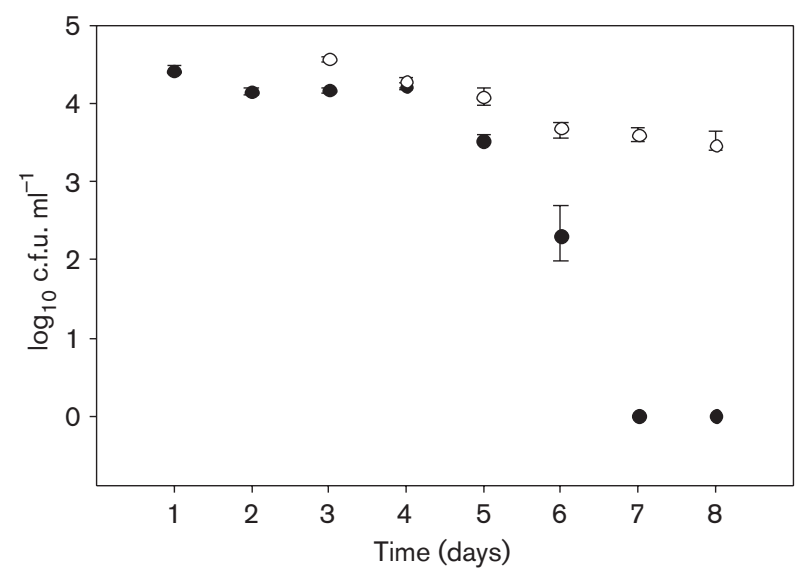

Fig. 4. Curative effect of $L$. fermentum $L 23(\bigcirc)$ on $E$. coli $(\bullet)$ in female BALB/c mice. Results are shown as means \pm SD. 
growth of pathogenic organisms, thus protecting against infection and consequently restoring the balance among microbial populations in the different tracts of the body (Mastromarino et al., 2002; Vintiñi et al., 2004). When probiotics are used in therapeutic trials or experiments, some protocol allowances are made, mainly to achieve optimal frequency and route of probiotic administration (Pavan et al., 2003). Even the bacterial flora present in the animal model could be a problem for the evaluation of the biotherapeutic effect of these beneficial micro-organisms. Moreover, some work has shown that lactobacilli are harboured by only a small percentage of mice (Meysick \& Garber, 1992). In other reports, minimal amounts of lactobacilli and a neutral $\mathrm{pH}$ were documented for various animals, suggesting that high numbers of lactobacilli and a low $\mathrm{pH}$ are characteristic of the human vagina (McGrory \& Garber, 1992).

Urinary tract infections are a common cause of illness among ambulatory and hospitalized patients, particularly within the female population. Among the agents of bacterial origin usually isolated, strains of $E$. coli are known to cause the greatest proportion of these infections (Reid, 2001; Foxman, 2002; Roos et al., 2006). In addition, E. coli, a typical inhabitant of the intestinal flora and a commensal of the vaginal flora, has been implicated in a large number of diseases (Watt et al., 2003; Xie et al., 2006). Many investigators have used $E$. coli to perform studies of urogenital infections (Asahara et al., 2001). For this reason, we considered this strain as a representative microorganism for our experiments in vivo.

Although the number of different micro-organisms in the vaginal population is difficult to quantify in vivo, evidence of their presence has been established by growth in vitro, microscopy and the use of identification tests. In the present study, microbiological analysis showed the absence of lactobacilli and Gram-negative bacilli/rods when the vaginal flora was evaluated as a prior step to our in vivo test and to avoid confusing results. In contrast, others have reported $25 \%$ lactobacilli as members of the vaginal microbiota of experimental animals, prior to challenge with a pathogenic micro-organism or before a preventative pre-inoculation with probiotic organisms (McGrory \& Garber, 1992; Zárate et al., 2007).

Our previous in vitro studies of the probiotic properties of L. fermentum L23 showed this strain to be an excellent candidate for adhesion to the vaginal epithelium. This strain showed intermediate hydrophobicity and an ability to self-aggregate and produce a biofilm on the surface of these cells (Pascual, 2004). The human strain L. fermentum L23 was able to colonize the vaginal tract of mice, after a single inoculation, for at least 4 days. This intravaginal administration showed a correlation between the colonization that we observed in vivo and the good adhesion properties we found in prior in vitro tests. Other authors (Silva de Ruiz et al., 2003; Czaja et al., 2007) have used a larger number of doses and oestradiol treatment (Vintiñi et al., 2004) to ensure the colonization of clinical lactic acid bacteria.

The clinical E. coli strain used in this experimental infection persisted in the animal model in high numbers for more than 7 days. This persistence was achieved without a pre-treatment to traumatize the mucosal surface, as was described by Asahara et al. (2001).

During evaluation of the preventative effect, L. fermentum L23 quickly resolved the pathogenic infection induced in our animal model. This is an important result, as a single, local pre-inoculation of our probiotic lactobacilli could successfully eliminate the pathogen only 3 days after the $E$. coli inoculation. This result is relevant if we compare it with the infection assay, where the pathogen remained for more than 7 days. Moreover, L23 inoculation into the vagina after an E. coli infection resulted in a complete cure, exhibiting a significant antimicrobial effect not only with a single pre-treatment but also in the post-infection treatment. These findings reaffirm the antimicrobial activity of L23 on 100 clinical E. coli strains observed by Pascual (2004) in previous experiments.

In summary, this study indicated that the probiotic bacterium L. fermentum strain L23 produced both preventative and curative effects on $E$. coli growth. It is likely that these beneficial properties and the production of bacteriocin and organic acids by strain L23 could act together in situ to inhibit the pathogenic micro-organism within the vaginal environment. In addition, a single dose of strain L23 is a good alternative compared with other therapies.

Many of the properties that are required to consider $L$. fermentum strain L23 a vaginal probiotic have already been identified. However, further studies are needed to determinate the best manner and timing of administration, the doses required and possible presence of side effects.

\section{ACKNOWLEDGEMENTS}

This work was supported by the Secretaría de Ciencia y Técnica de la Universidad Nacional de Río Cuarto. W. G. is a Career Member of CONICET (Consejo Nacional de Investigaciones Científicas y Técnicas), Argentina. F. R. has a doctoral fellowship from CONICET. The authors thank Dr M. Philipp for editing the manuscript.

\section{REFERENCES}

Alander, M., Satokari, R., Korpela, R., Saxelin, M., VilpponenSalmela, T., Mattila-Sandholm, T. \& von Wright, A. (1999). Persistence of colonization of human colonic mucosa by a probiotic strain, Lactobacillus rhamnosus GG, after oral consumption. Appl Environ Microbiol 65, 351-354.

Asahara, T., Nomoto, K., Watanuki, M. \& Yokokura, T. (2001). Antimicrobial activity of intraurethrally administered probiotic Lactobacillus casei in a murine model of Escherichia coli urinary tract infection. Antimicrob Agents Chemother 45, 1751-1760. 
Bergey's Manual of Determinative Bacteriology (1994). 9th edn, pp. 71-174, 175-289, 527-558. Edited by J. G. Holt. Baltimore: Williams \& Wilkins.

Chan, R. C., Reid, G., Irvin, R. T., Bruce, A. W. \& Costerton, J. W. (1985). Competitive exclusion of uropathogens from human uroepithelial cells by Lactobacillus whole cells and cell wall fragments. Infect Immun 47, 84-89.

Colodner, R., Edelstein, H., Chazan, B. \& Raz, R. (2003). Vaginal colonization by orally administered Lactobacillus rhamnosus GG. Isr Med Assoc J 5, 767-769.

Czaja, C. A., Stapleton, A. E., Yarova-Yarovaya, Y. \& Stamm, W. E. (2007). Phase I trial of a Lactobacillus crispatus vaginal suppository for prevention of recurrent urinary tract infection in women. Infect Dis Obstet Gynecol 2007, 35387.

de Champs, C., Maroncle, N., Balestrino, D., Rich, C. \& Forestier, C. (2003). Persistence of colonization of intestinal mucosa by a probiotic strain, Lactobacillus casei subsp. rhamnosus Lcr35, after oral consumption. J Clin Microbiol 41, 1270-1273.

Forbes, B. A., Sahm, D. F. \& Weissfeld, A. (2004). Bailey \& Scott's Diagnostic Microbiology, 11th edn, pp. 297, 379. St Louis, MO: Mosby.

Foxman, B. (2002). Epidemiology of urinary tract infections: incidence, morbidity, and economic costs. Am J Med 113, 5-13.

Kontiokari, T., Sundqvist, K., Nuutinen, M., Pokka, T., Koskela, M. \& Uhari, M. (2001). Randomised trial of cranberry-lingonberry juice and Lactobacillus GG drink for the prevention of urinary tract infections in women. BMJ 322, 1571.

Lennette, E. H., Ballows, A., Hausler, W. J. \& Shadomy, H. J. (editors) (1987). Manual of Clinical Microbiology, 4th edn, pp. 336-359. Washington, DC: American Society for Microbiology.

Mastromarino, P., Brigidi, P., Macchia, S., Maggi, L., Pirovano, F., Trinchieri, V., Conte, U. \& Matteuzzi, D. (2002). Characterization and selection of vaginal Lactobacillus strains for the preparation of vaginal tablets. J Appl Microbiol 93, 884-893.

McGrory, T. \& Garber, G. E. (1992). Mouse intravaginal infection with Trichomonas vaginalis and role of Lactobacillus acidophilus in sustaining infection. Infect Immun 60, 2375-2379.

Meysick, K. C. \& Garber, G. E. (1992). Interactions between T. vaginalis and vaginal flora in a mouse model. J Parasitol 78, 157-160.

Nigatu, A., Ahrne, S. \& Molin, G. (2000). Temperature-dependent variation in API $50 \mathrm{CH}$ fermentation profiles of Lactobacillus species. Curr Microbiol 41, 21-26.

Pascual, L. M. (2004). Bacteriocinogenia en el género Lactobacillus: características benéficas de lactobacilos de vagina humana. Doctoral thesis, Universidad Nacional de Río Cuarto, Argentina.

Pascual, L. M., Daniele, M. B., Giordano, W., Pajaro, M. C. \& Barberis, I. L. (2008a). Purification and partial characterization of novel bacteriocin L23 produced by Lactobacillus fermentum L23. Curr Microbiol 56, 397-402.

Pascual, L. M., Daniele, M. B., Ruiz, F., Giordano, W., Pajaro, C. \& Barberis, L. (2008b). Lactobacillus rhamnosus L60, a potential probiotic isolated from the human vagina. J Gen Appl Microbiol 54, 141-148.

Pavan, S., Desreumaux, P. \& Mercenier, A. (2003). Use of mouse models to evaluate the persistence, safety and immune modulation capacities of lactic acid bacteria. Clin Diagn Lab Immunol 10, 696701.

Peran, L., Sierra, S., Cmalada, M., Lara Villoslada, F., Bailón, E., Nieto, A., Concha, C., Olivares, M., Zarzuelo, A. \& other authors (2007). A comparative study of the preventive effects exerted by two probiotics, Lactobacillus reuteri and Lactobacillus fermentum, in the trinitrobenzenesulfonic acid model of rat colitis. Br J Nutr 97, 96-103.

Reid, G. (2001). Probiotic agents to protect the urogenital tract against infection. Am J Clin Nutr 73, 437S-443S.

Reid, G. (2002). Probiotics for urogenital health. Nutr Clin Care 5, 3-8.

Reid, G., Jass, J., Sebulsky, M. T. \& McCormick, J. K. (2003). Potential uses of probiotics in clinical practice. Clin Microbiol Rev 16, 658-672.

Reid, G., Anand, S., Bingham, M., Wadstrom, T., Fuller, R., Anukam, K. \& Katsivo, M. (2005). Probiotics for the developing world. J Clin Gastroenterol 39, 485-488.

Roos, V., Ulett, G., Schembri, M. \& Klemm, P. (2006). The asymptomatic bacteriuria Escherichia coli strain 83972 outcompetes uropathogenic E. coli strains in human urine. Infect Immun 74, 615624.

Silva de Ruiz, C., Rey, M. del R. \& Nader-Macias, M. (2003). Structural and ultrastructural studies of the urinary tract of mice inoculated with Lactobacillus fermentum. BJU Int 91, 878-882.

Vintiñi, E., Ocana, V. \& Nader-Macias, M. (2004). Effect of lactobacilli administration in the vaginal tract of mice: evaluation of side effects and local immune response to local administration of selected strains. Methods Mol Biol 268, 401-410.

Wagner, R. D., Pierson, C., Warner, T., Dohnalek, M., Farmer, J., Roberts, L., Hilty, M. \& Balish, E. (1997a). Biotherapeutic effects of probiotic bacteria on candidiasis in immunodeficient mice. Infect Immun 65, 4165-4172.

Wagner, R. D., Warner, T., Roberts, L., Farmer, J. \& Balish, E. (1997b). Colonization of congenitally immunodeficient mice with probiotic bacteria. Infect Immun 65, 3345-3351.

Watt, S., Lanotte, P., Mereghetti, L., Moulin-Schouleur, M., Picard, B. \& Quentin, R. (2003). Escherichia coli strains from pregnant women and neonates: intraspecies genetic distribution and prevalence of virulence factors. J Clin Microbiol 41, 1929-1935.

Xie, J., Foxman, B., Zhang, L. \& Marrs, C. (2006). Molecular epidemiologic identification of Escherichia coli genes that are potentially involved in movement of the organism from the intestinal tract to the vagina and bladder. J Clin Microbiol 44, 2434-2441.

Zárate, G., Santos, V. \& Nader-Macias, M. E. (2007). Protective effect of vaginal Lactobacillus paracasei CRL 1289 against urogenital infection produced by Staphylococcus aureus in a mouse animal model. Infect Dis Obstet Gynecol 2007, 48358. 